\title{
Advantageous conditions of saccharification of lignocellulosic biomass for biofuels generation via fermentation processes
}

\author{
Karolina Kucharska $^{1}$ (D) Edyta Słupek ${ }^{1} \cdot$ Hubert Cieśliński $^{2} \cdot$ Marian Kamiński $^{1}$
}

Received: 30 June 2019 / Accepted: 11 October 2019/ Published online: 21 October 2019

(c) The Author(s) 2019

\begin{abstract}
Processing of lignocellulosic biomass includes four major unit operations: pre-treatment, hydrolysis, fermentation and product purification prior to biofuel generation via anaerobic digestion. The microorganisms involved in the fermentation metabolize only simple molecules, i.e., monosugars which can be obtained by carrying out the degradation of complex polymers, the main component of lignocellulosic biomass. The object of this paper was to evaluate the saccharification conditions and identify the process parameters that should be applied to improve the saccharification efficiency of lignocellulosic biomass, defined as the simple sugars concentration, which was considered as a crucial parameter for hydrogen generation via dark fermentation. Drawing global conclusions about the occurring changes in the biomass requires learning about the nature of the biomass structure and composition at different stages of the process. Therefore, techniques for analysis, as FTIR, HPLC and SEM were applied. The experiment was planned employing Box-Behnken design. The advantageous operating conditions and the composition of saccharification enzymatic cocktail were identified and their values occurred similar in the applied border conditions for all tested biomass types. Analysis of the intermediate solid and liquid streams generated during the pre-treatment procedure revealed several structural and compositional changes in the biomass.
\end{abstract}

Keywords Lignocellulosic biomass $\cdot$ Saccharification biohydrogen $\cdot$ Fermentation $\cdot$ Process control methods

\section{Introduction}

The trend to produce second-generation biofuels from nonconsumer raw materials increases. The recovery of energy and the reduction of the content of organic waste are the benefits of the lignocellulosic residue application within the bioconversion processes. Biomass residues contain lignocellulose that is composed mainly of cellulose (about $50 \% \mathrm{wt}$.),

This work was presented at the 44th International Conference of Slovak Society of Chemical Engineering held in Tatranské Matliare on May 21-25, 2018.

Karolina Kucharska

karolina.kucharska@pg.edu.pl

1 Faculty of Chemistry, Department of Process Engineering and Chemical Technology, Gdańsk University of Technology, Narutowicza 11/12 Street, 80-233 Gdańsk, Poland

2 Faculty of Chemistry, Department of Molecular Biotechnology and Microbiology, Gdańsk University of Technology, Narutowicza 11/12 Street, Gdańsk 80-233, Poland hemicellulose (about 30\% wt.) and lignin (about 20\% wt.) (Kumar and Sharma 2017). The content of the individual components may vary significantly for different types of biomass and even for the same type of biomass obtained from different regions (Anwar et al. 2014). About 48\% of the biomass-originating energy comes from processing of lignocellulosic materials (Balat 2011; Sun and Cheng 2002). The development of technologies for lignocellulosic biomass processing focuses mainly on biofuel generation and biorafination processes regarding the waste streams. The products of biorafination include varied organic chemical compounds, i.e., biomaterials and biochemicals, and biofuels, among which the most important are bioethanol, biohydrogen, biodiesel and furan biofuels (Balat 2011; Lalak et al. 2014).

The processing of lignocellulosic biomass to hydrogen includes four major unit operations: pre-treatment, hydrolysis, fermentation and product purification. Pre-treatment includes milling, mincing and biomass conditioning; it is a high-cost consuming process. Size reduction of biomass particles is used for most lignocellulosic raw materials and it is realized by means of fragmentation, grinding, milling or defibering. The hydrolysis is carried by means of chemical, 
enzymatic or biological pre-treatment (Wi 2015). The initial alkaline (Kucharska et al. 2018) and/or oxidative treatment increase the efficiency of saccharification. Therefore, pre-treatment of lignocellulose material by alkaline and/or oxidative hydrolysis is a key step in facilitating the release of simple sugars during enzymatic hydrolysis from cellulose and hemicellulose present in it. Based on the conducted experiments, it is found that the availability of cellulose for enzymes is an individual feature depending on the structure and method of combining individual elements of lignocellulose in biomass. The microorganisms involved in the targeted dark fermentation metabolize more easily simple sugar molecules, especially glucose, that can be obtained by degrading the mentioned polysaccharides, which are the main component of lignocellulosic biomass. For the effective modification of the complex structure of lignocellulosic materials, it is necessary to determine the optimal, balanced combination of cellulolytic enzyme mixtures. Based on the literature review, it was found that the introduction of $\beta$-glucosidase into the proposed enzyme cocktail increases the efficiency of cellulose hydrolysis to monosaccharides (Alvira et al. 2010), due to the fact that the intermediate enzymatic cellulose hydrolysis, i.e., cellobiose is an inhibitor of cellulolytic enzymes (endo- and exogenous cellulases).

Polysaccharide accessibility can be increased by redistribution or lignin and/or hemicellulose removal. This purpose is carried during alkaline hydrolysis and leads to the increase in material porosity and a decrease of the cellulose crystallinity (Brodeur et al. 2011). These various processes contribute to facilitate the access of enzymes to polysaccharides to perform their hydrolysis and saccharification reactions. The efficiency of the subsequent release of simple sugars during the enzymatic hydrolysis, i.e., saccharification, strongly depends on the size of the biomass particles. Hydrolysates obtained during the second step may be used for biofuels generation via fermentative processes, e.g., for hydrogen generation during dark fermentation (Kumar et al. 2015b; Agbor et al. 2011). Parameters affecting the efficiency of saccharification were investigated by a wide group of researchers. However, the published results do not give a complex answer regarding the process parameters that should be applied for diversified lignocellulosic materials.

The components of the enzymatic cocktail for pre-treated lignocellulosic biomass saccharification are object of development. Simple sugars must be released from crystalline cellulose and hemicellulose via enzymatic hydrolysis to be introduced to further bioconversion processes as feed material. Therefore, the efficiency of enzymatic hydrolysis is crucial as conversion of biomass to the desired products is concerned (Kucharska et al. 2018, Narra et al. 2015). High saccharification efficiency is a criterion for process parameters selection, as the process is cost consuming. Cellulose and hemicellulose conversion is catalysed by cellulases, i.e., endoglucanases (digest $\beta$-1,4-glicosidic bonds inside amorphic regions of cellulose chains and release oligosaccharides molecules), exoglucanases (release monomers and dimers, i.e., cellobiose from the end of the cellulose chains) and $\beta$-glycosylases (release glucose from cellobiose) and hemicellulases, i.e., endoxylanases and $\beta$-xylosidases, $\alpha$-glucuronidase, $\alpha$-arabinofuranosidase and acetoxylan esterase, $\beta$-mannanase and $\beta$-mannosidase. Each enzyme proposed in the enzymatic cocktail is characterized with a different optimal range of working temperature and $\mathrm{pH}$, therefore, it is crucial to determine the operational range for specific enzymatic cocktail.

To determine the proportions between enzymatically components, studies based on the $3 \mathrm{k}$ Box-Behnken statistical design have been made, including variables such as cellulase ( $\beta$-glucosidase from Aspergillus niger, SigmaAldrich) content in the enzymatic cocktail, temperature and enzymatic hydrolysis time, as a parameter modeled using the final glucose concentration in the hydrolysate. However, the results of research on the optimization of the composition of the enzyme cocktail are still being developed. Studies regarding the immobilization of enzymes were also carried (Kucharska et al. 2018). From the point of view of the efficiency of enzymatic hydrolysis, it was found that a stream separation regarding liquids after alkaline hydrolysis and solid-state residues makes it possible to obtain results that are reproducible and comparable with the yields obtained as a result of acid hydrolysis (Trzcinski and Stuckey 2015; Hasegawa et al. 2013).

Hence, the object of this paper is to evaluate the advantageous saccharification conditions and identify the process parameters that should be applied to improve the saccharification efficiency of lignocellulosic biomass, defined as the simple sugars concentration, which is considered as a crucial parameter for hydrogen generation via dark fermentation.

\section{Experimental}

\section{Materials and methods}

\section{Biomass origin, collection and preparation}

Several types of biomass residues were chosen as the source of lignocellulose. A representant of cereals, i.e., terrestrial part of waste triticale (abr. TP) (Triticulum ssp. harvested in September 2017 originated from a local farm in Pomeranian Voivodeship, Poland, (54.632,618N, 18.247,050E); grass type residue, i.e., meadow grass (abr. MG) harvested in August 2016, originated from a local farm in Pomeranian Voivodeship, Poland, (54.370,719N 18.399,078E); wood type residue, i.e., beech (abr. B) harvested in October 2016 originated from a local forest in Pomeranian Voivodeship, 
Poland, $(54.601,425 \mathrm{~N} 18.175,480 \mathrm{E})$ were used as the lignocellulosic biomass in this study. A Meec Tools garden shredder 425 and RETCH Ultra Centrifugal Mill ZM 200 ( $0.75 \mathrm{~mm}$ screen) were used for materials milling and mincing. Before introducing to alkaline hydrolysis, the material was dried in a laboratory dryer at $105^{\circ} \mathrm{C}$ for $4 \mathrm{~h}$ according to previously prepared procedures (Sluiter et al. 2008a, Sluiter et al. 2008b; Sluiter et al. 2008c). The composition of lignocellulosic materials was determined according to the National Renewable Energy Laboratory (NREL) analytical procedures.

\section{Alkaline hydrolysis}

Significant statistical parameters for alkaline hydrolysis were identified during previous experiments with the Box-Behnken design. Therefore, in this study, the authors have applied the optimal values to carry further research for saccharification optimization. Monoethanoloamine (abr. MEA) was used (Kucharska et al. 2018) at concentration of $21 \%(\mathrm{v} / \mathrm{v})$. Former research has shown that there is a possibility to re-use MEA reagent (Kucharska et al. 2018). The temperature of process was equal to $65^{\circ} \mathrm{C}$ and the hydrolysis lasted $16 \mathrm{~h}$. Alkaline hydrolysis promotes the formulation of lignin derivatives, which may be further processed during biorafination. Such by-products can become value-added products. Its further processing may offset apparatus costs related to the corrosion of the materials for apparatus. Due to the presence of lignin derivatives in the liquid fraction, the solid residues were separated and washed. The solidstate residues were then introduced to enzymatic hydrolysis (Wikandari et al. 2016).

\section{Enzymatic hydrolysis}

Based on the literature review, it was found that the introduction of $\beta$-glucosidase into the proposed enzyme cocktail increases the efficiency of cellulose hydrolysis to monosaccharides, due to the fact that the intermediate enzymatic cellulose hydrolysis, i.e., cellobiose, is an inhibitor of cellulolytic enzymes. Since $\beta$-glucosidase is the most expensive of the components of the enzyme cocktail being developed, to determine the proportion between its components, studies based on Box-Behnken design have been made. Parameters identified as statistically significant during preliminary tests were $\beta$-glucosidase content in the enzyme cocktail $(\mathrm{m} / \mathrm{m}-$ ratio of $\beta$-glucosidase mass to the mass of other enzymes in the cocktail), temperature, $\mathrm{pH}$ and enzymatic hydrolysis time, as an out coming modeled parameter using the final glucose concentration in the hydrolysate.

The solid residue after the alkaline pre-treatment was introduced into cellulolytic enzymes cocktail, after thorough washing with water and acetone, containing Viscozyme L
(Novozymes Corp., Copenhagen Denmark) supplemented with $\beta$-glucosidase (Sigma-Aldrich, Stockholm, Sweden). $200 \mathrm{~mL}$ of enzymatic solution (Viscozyme L: Glucosidase from Aspergillus niger; at different proportions) with $10 \mathrm{~g}$ of solid lignocellulosic residue in McIlvaine's buffer was stirred in a shaker at different temperatures in the range of $30-48{ }^{\circ} \mathrm{C}$ for $6-96 \mathrm{~h}$ in $\mathrm{pH}$ equal to $4.2-5.8$. Subsequently, samples were collected and before analysis, the enzymes were separated by heating to $60{ }^{\circ} \mathrm{C}$ and centrifugation (Hettich zentrifugen, D-78,533 Tuttlingen, 3000 RPM).

\section{Fundamental energy, economic balance and risk assessment}

The operational costs and energy requirement during the applied laboratory scale experiment were carried with respect to pre-treatment of energetic willow in former study (Lukajtis et al. 2018). An exemplary economic analysis of the energetic willow alkaline pre-treatment showed that biomass preparation using mechanical methods, the alkaline pre-treatment with special respect to temperature significantly affect the costs of the process. As a result of this research, it was stated that to reduce the costs of biomass processing, the optimal values of process parameters identification is required. The authors have optimized parameters regarding alkaline pre-treatment (Lukajtis et al. 2018), however, the saccharification step also required analysis regarding the used border conditions. Therefore, the authors found it reasonable to compare the efficiency and relative increase in glucose efficiency for the process parameters during enzymatic saccharification with expansion to diversified lignocellulosic materials.

During the applied procedure, different chemical substances, solvents, enzymes and microorganisms were engaged. Therefore, in case of scale up from laboratory scale to quarter-technical scale a risk management procedure needs to be considered and introduced. Risk assessment is one of the key management tools of any modern organization, as the term risk is permanently inscribed in all areas of organization management at both the strategic and operational levels. The obligation to conduct systematic risk analysis is defined by legal regulations in the field of management control, protection of personal data, quality management system (ISO 9001), information security (ISO 27,001 ), business continuity (ISO 22,301) or anti-corruption system (ISO 37,001). The analysis of possible hazards regarding the process and their occurrence is presented in Table 1.

\section{Analytical methods}

Biomass, alkaline pre-treated biomass and enzymatic hydrolysates composition determination Total solids, ash 
Table 1 Critical hazards and consequences related with the emissions during pre-treatment, saccharification and bioconversion processes

\begin{tabular}{|c|c|c|c|}
\hline \multirow[t]{2}{*}{ Consequence } & \multicolumn{3}{|l|}{ Critical hazard } \\
\hline & Environmental cost & Financial consequences & Injury \\
\hline Severe & $\begin{array}{l}\text { Emission of chemicals due to multiple } \\
\text { fatalities }\end{array}$ & Total loss of the equipment & Sickness caused by an accident at work \\
\hline Major & $\begin{array}{l}\text { Emission of chemicals due to single } \\
\text { fatality }\end{array}$ & Total loss of the charge & $\begin{array}{l}\text { Health complications related to the nature } \\
\text { of the work performed }\end{array}$ \\
\hline Minor & Incidents or minor damages & $\begin{array}{l}\text { Eliminable error in one of the stages of } \\
\text { the process }\end{array}$ & $\begin{array}{l}\text { Nuisance associated with repetition of } \\
\text { activities }\end{array}$ \\
\hline Insignificant & Barely noticeable loss of the chemicals & Incident with small impact on the costs & $\begin{array}{l}\text { Short-term absence with little effect on the } \\
\text { process }\end{array}$ \\
\hline
\end{tabular}

and extractives for TP, MG and B before and after alkaline pre-treatment were determined according to the National Renewable Energy Laboratory (NREL) analytical procedures (Sluiter et al. 2008a, b, c, Kucharska et al. 2018).

The concentration of glucose, xylose, arabinose, mannose, galactose and cellobiose in enzymatic hydrolysates were determined using HPLC (Nowak et al. 2017). For the purposes of HPLC, collected samples were purified via cationite and anionite ion exchange columns and filtered through a syringe filter, to remove buffers and protein before the analysis. Nitrogen evaporated sample was next dissolved in $200 \mu \mathrm{L}$ of water and directed to HPLC analysis (injection volume $50 \mu \mathrm{L}$, HPLC-RID; temperature $60{ }^{\circ} \mathrm{C}$; Rezex $\mathrm{Pb}^{2+}$ column $(300 \times 7.8 \mathrm{~mm}, 8 \mu \mathrm{m}$, Phenomenex, Torrance, CA, USA; eluent: water; flow: $0.6 \mathrm{~mL} /$ min. Each analysis was carried in triplicate. Control experiments were carried without the addition of solid residues.

Lignin derivatives determination in alkaline hydrolysates The presence and concentration of lignin derivatives, i.e., hydroxymethylfurfural, 5-HMF and total phenolic compounds were determined by QP2010 GC-MS $\mathrm{SE}$ gas chromatograph-mass spectrometer (Shimadzu, Japan) equipped with a combi-PAL AOC 5000 autosampler (Shimadzu, Japan) and a $60 \mathrm{~m} \times 0.25 \mathrm{~mm} \times 1.40 \mu \mathrm{m}$ Rxi-624Sil MS capillary column (Restek, USA). Lab Solutions software (Shimadzu, Japan) with NIST 14 mass spectra library were used for data management (Słupek et al. 2018).

Scanning electron spectroscopy (SEM) and energy-dispersive X-ray spectroscopic measurements (EDX) Samples of solid-state residues of lignocellulosic biomass before and after enzymatic hydrolysis were dried and gold-covered by sputtering method (sputter coater Quorum Q150TE, Quorum Technologies Ltd, Lewes, UK). SEM images were performed using SEM Zeiss EVO-40 (Carl Zeiss Microscopy $\mathrm{GmbH}$, Jena, Germany). Energy-dispersive X-ray spectroscopic measurements (EDX measurements) were carried out using EDS Bruker AXS Quantax 200 (Billerica, MA, USA) to reveal the elemental composition of investigated materials, applied samples were not gold sputtered.

Fourier transform infrared (FTIR) spectroscopy Fourier transformation infrared spectroscopy (MIR-FT-IR) was applied using the Nicolet 8700 Spectrometer (Thermo Scientific) to identify the types of chemical bonds in structural units of the obtained lignocellulosic particles before and after pre-treatment. The method of suppressed total reflection (ATR) was used. The infrared spectra were registered from 4500 to $524 \mathrm{~cm}^{-1}$ at $2 \mathrm{~cm}^{-1}$ resolution using air as the background.

\section{Results and discussion}

\section{Enzymatic cocktail composition and saccharification parameters optimization}

As an outcome of the Response Surface Methodology (abr. RSM) data analysis for Box-Behnken design variables presented in Table 2, a model equation for each lignocellulosic material was defined. Equations, determination coefficients and optimal values of variables are presented in Table 3.

The presented models are valid in the operational model conditions, i.e. in the range of $0.01-0.09$ for $\beta$-glucosidase content $[\mathrm{m} / \mathrm{m}], 4-5.6$ for $\mathrm{pH}, 30-40{ }^{\circ} \mathrm{C}$ for temperature and 20-48 $\mathrm{h}$ for saccharification time.

Even though several differences occurred when the models were calculated, the range of optimal values for different lignocellulosic materials calculated on the basis of the response surface methodology revealed, that the optimal values regarding process parameters and composition of enzymatic cocktail remained at a constant level (in the range of $2 \%$ ). Therefore, to evaluate the changes occurring in the biomass structure and composition, occurring during optimized alkaline pre-treatment and optimized saccharification measurements regarding the 
Table 2 Box-Behnken design for optimisation of enzymatic saccharification for TP, MG and $\mathrm{B}$

\begin{tabular}{|c|c|c|c|c|c|c|c|}
\hline \multirow[t]{2}{*}{$\begin{array}{l}\text { Number of } \\
\text { experiment }\end{array}$} & \multirow{2}{*}{$\begin{array}{l}\beta \text {-glucosidase } \\
\text { content }[\mathrm{m} / \mathrm{m}] \\
X 1\end{array}$} & \multirow{2}{*}{$\begin{array}{l}\mathrm{pH} \\
X 2\end{array}$} & \multirow{2}{*}{$\begin{array}{l}t\left[{ }^{\circ} \mathrm{C}\right] \\
X 3\end{array}$} & \multirow{2}{*}{$\begin{array}{l}\tau[\mathrm{h}] \\
X 4\end{array}$} & \multicolumn{3}{|c|}{$\begin{array}{l}\text { Glucose concentration [mg/ } \\
\left.\mathrm{g}_{\text {biomass }}\right]\end{array}$} \\
\hline & & & & & $Y(\mathrm{TP})$ & $Y(\mathrm{MG})$ & $Y(\mathrm{~B})$ \\
\hline 1. & 0.01 & 4 & 35 & 34 & 191.3 & 156.1 & 214.4 \\
\hline 2. & 0.09 & 4 & 35 & 34 & 344.7 & 276.7 & 389.2 \\
\hline 3. & 0.01 & 5.6 & 35 & 34 & 226.3 & 183.7 & 254.3 \\
\hline 4. & 0.09 & 5.6 & 35 & 34 & 312.2 & 251.2 & 352.2 \\
\hline 5. & 0.01 & 4.8 & 30 & 34 & 276.4 & 223.1 & 311.4 \\
\hline 6. & 0.09 & 4.8 & 30 & 34 & 317.6 & 255.5 & 358.4 \\
\hline 7. & 0.01 & 4.8 & 40 & 34 & 217.5 & 176.7 & 244.2 \\
\hline 8. & 0.09 & 4.8 & 40 & 34 & 343.2 & 275.6 & 387.5 \\
\hline 9. & 0.01 & 4.8 & 35 & 20 & 188.4 & 153.8 & 211.1 \\
\hline 10. & 0.09 & 4.8 & 35 & 20 & 321.2 & 258.3 & 362.5 \\
\hline 11. & 0.01 & 4.8 & 35 & 48 & 218.4 & 177.4 & 245.3 \\
\hline 12. & 0.09 & 4.8 & 35 & 48 & 429.0 & 343.1 & 485.4 \\
\hline 13. & 0.05 & 4 & 30 & 34 & 357.1 & 286.5 & 403.4 \\
\hline 14. & 0.05 & 5.6 & 30 & 34 & 288.7 & 232.7 & 325.4 \\
\hline 15. & 0.05 & 4 & 40 & 34 & 290.2 & 233.9 & 327.1 \\
\hline 16. & 0.05 & 5.6 & 40 & 34 & 365.2 & 292.9 & 412.6 \\
\hline 17. & 0.05 & 4 & 35 & 20 & 312.4 & 251.3 & 352.4 \\
\hline 18. & 0.05 & 5.6 & 35 & 20 & 276.8 & 223.3 & 311.8 \\
\hline 19. & 0.05 & 4 & 35 & 48 & 315.2 & 253.6 & 355.6 \\
\hline 20. & 0.05 & 5.6 & 35 & 48 & 343.1 & 275.5 & 387.4 \\
\hline 21. & 0.05 & 4.8 & 30 & 20 & 288.7 & 232.7 & 325.4 \\
\hline 22. & 0.05 & 4.8 & 40 & 20 & 241.3 & 195.5 & 271.4 \\
\hline 23. & 0.05 & 4.8 & 30 & 48 & 287.5 & 231.8 & 324.1 \\
\hline 24. & 0.05 & 4.8 & 40 & 48 & 422.9 & 338.3 & 478.4 \\
\hline 25. & 0.05 & 4.8 & 35 & 34 & 356.3 & 285.9 & 402.5 \\
\hline
\end{tabular}

Table 3 Model equations based on RSM for different lignocellulosic materials

\begin{tabular}{|c|c|c|c|c|c|c|}
\hline \multirow{2}{*}{$\begin{array}{l}\text { Lignocel- } \\
\text { lulosic } \\
\text { material }\end{array}$} & \multirow[t]{2}{*}{ Model equation } & \multirow[t]{2}{*}{$R^{2}$} & \multicolumn{4}{|c|}{ Optimal values } \\
\hline & & & $X 1$ & $X 2$ & $X 3$ & $X 4$ \\
\hline $\mathrm{TP}$ & $\begin{array}{l}Y(\mathrm{TP})=356.32+62.46 X 1+0.12 X 2+5.34 X 3+32.28 X 4-53.85 X 1^{2}-24.25 X 2^{2}-21.51 \\
X 3^{2}-16.86 X 1 X 2+21.17 X 1 X 3+19.45 X 1 X 4+15.88 X 2 X 3+45.68 X 3 X 4\end{array}$ & 0.92 & 0.06 & 4.82 & 37 & 48 \\
\hline MG & $\begin{array}{l}Y(\mathrm{MG})=285.91+49.13 X 1+9.2 X 2+4.2 X 3+25.39 X 4-42.35 X 1^{2}-19.08 X 2^{2}-11.87 X 3^{2}-16.92 \\
X 4^{2}-13.27 X 1 X 2+16.61 X 1 X 3+15.3 X 1 X 4+28.2 X 2 X 3+12.49 X 2 X 4+35.93 X 3 X 4\end{array}$ & 0.90 & 0.06 & 4.83 & 36 & 48 \\
\hline B & $\begin{array}{l}Y(\mathrm{~B})=402.5+71.21 X 1+0.13 X 2+6.09 X 3+36.8 X 4-61.38 X 1^{2}-27.65 X 2^{2}-17.21 X 3^{2}-24.52 \\
X 4^{2}-19.23 X 1 X 2+24.075 X 1 X 3+22.18 X 1 X 4+40.87 X 2 X 3+18.1 X 2 X 4+52.075 X 3 X 4\end{array}$ & 0.91 & 0.06 & 4.78 & 36 & 48 \\
\hline
\end{tabular}

biomass at different stages of pre-treatment were carried. The other authors have also reported a possibility to apply response surface methodology to describe the effectiveness of the process. (Dahunsi et al. 2017; Ko et al. 2009; Lay 2001; Lay et al. 2005; Sangyoka et al. 2016; Sekoai 2016). However, in mentioned papers, the authors focused on one type of raw material and its processing. The goal of carried research is to carry an effort to compare the results obtained for three types of biomass to draw global conclusions in the studied range of variability.

\section{Biomass composition at different stages of pre-treatment}

Changes in the composition of TP, MG and B occurring during pre-treatment steps regarding lignin, cellulose, hemicellulose and their derivatives content are presented 
Table 4 Content of cellulose, lignin, hemicellulose in solid-state residues of lignocellulosic biomasses (TP, MG and B) at pre-treatment stages

\begin{tabular}{|c|c|c|c|c|c|c|c|c|}
\hline Biomass & $\begin{array}{l}\text { Cellulose } \\
\text { content [\%] }\end{array}$ & $\begin{array}{l}\text { Hemicellulose } \\
\text { content }[\%]\end{array}$ & Lignin content $[\%]$ & $\begin{array}{l}\text { Ash and extrac- } \\
\text { tives (ethanol) } \\
{[\%]}\end{array}$ & $\begin{array}{l}\text { Cellulose } \\
\text { removal [\%] }\end{array}$ & $\begin{array}{l}\text { Hemicellulose } \\
\text { removal [\%] }\end{array}$ & $\begin{array}{l}\text { Lignin } \\
\text { removal } \\
{[\%]}\end{array}$ & $\begin{array}{l}\text { Total biomass } \\
\text { amount recovery } \\
{[\%]}\end{array}$ \\
\hline \multicolumn{9}{|c|}{ Raw biomass } \\
\hline $\mathrm{TP}$ & 39.1 & 25.4 & 18.4 & 7.1 & - & - & - & - \\
\hline MG & 27.1 & 22.6 & 16.8 & 33.5 & - & - & - & - \\
\hline B & 38.6 & 19.9 & 28.3 & 13.2 & - & - & - & - \\
\hline \multicolumn{9}{|c|}{ Solids after optimized MEA-pre-treatment } \\
\hline TP & 38.8 & 21.5 & 1.4 & n.d. & 0.8 & 15.4 & 92.5 & 55.5 \\
\hline MG & 26.7 & 19.8 & 3.3 & n.d. & 1.4 & 12.4 & 80.2 & 59.1 \\
\hline B & 38.6 & 17.6 & 6.2 & n.d. & $<$ LOD & 11.4 & 79.9 & 73.6 \\
\hline \multicolumn{9}{|c|}{ Solids after optimized saccharification } \\
\hline $\mathrm{TP}$ & 3.4 & 4.2 & $<$ LOD & n.d. & 91.2 & 80.5 & $<$ LOD & 12.0 \\
\hline MG & 2.2 & 3.1 & $<$ LOD & n.d. & 91.8 & 84.3 & $<$ LOD & 8.5 \\
\hline B & 1.1 & 2.3 & $<$ LOD & n.d. & 99.5 & 86.9 & $<$ LOD & 6.1 \\
\hline
\end{tabular}

n.d. not detected, $L O D$ limit of detection, $L O D 0.5 \%$, [\%] content of constituents, i.e., cellulose, hemicellulose or lignin after pre-treatment steps is presented as a content of each polymer in the initial material $[\mathrm{m} / \mathrm{m}]$, respectively; standard deviation for data in the table, $\mathrm{SD}=0.8 \%$

Table 5 Composition of alkaline and enzymatic hydrolysate liquid streams after optimized pre-treatment stages of lignocellulosic biomasses (TP, MG and B)

\begin{tabular}{|c|c|c|c|c|c|c|c|}
\hline \multirow[t]{2}{*}{ Hydrolysate } & \multicolumn{2}{|c|}{ Lignin and hemicellulose derivatives } & \multicolumn{4}{|l|}{ Monosugars } & \multirow[t]{2}{*}{ Cellobiose, g/L } \\
\hline & $\begin{array}{l}\text { Sum of TPC, HMF } \\
\text { and furfural, g/L }\end{array}$ & Levulinic acid g/L & Glucose $\mathrm{g} / \mathrm{L}$ & Xylose $\mathrm{g} / \mathrm{L}$ & Galactose $\mathrm{g} / \mathrm{L}$ & $\begin{array}{l}\text { Mannose, } \\
\text { arabinose g/L }\end{array}$ & \\
\hline \multicolumn{8}{|c|}{ Alkaline hydrolysate } \\
\hline $\mathrm{TP}$ & 0.870 & 0.06 & $<\mathrm{LOD}$ & 0.09 & 0.05 & 0.05 & 0.03 \\
\hline MG & 0.105 & 0.07 & 0.08 & 0.07 & 0.02 & 0.05 & $<\mathrm{LOD}$ \\
\hline B & 0.200 & 0.02 & $<$ LOD & 0.07 & 0.06 & 0.05 & $<\mathrm{LOD}$ \\
\hline \multicolumn{8}{|c|}{ Enzymatic hydrolysate } \\
\hline $\mathrm{TP}$ & $<\mathrm{LOD}$ & $<$ LOD & 1.28 & 0.32 & 0.12 & 0.06 & 0.04 \\
\hline MG & $<$ LOD & $<\mathrm{LOD}$ & 0.84 & 0.28 & 0.15 & 0.18 & 0.03 \\
\hline $\mathrm{B}$ & $<$ LOD & $<\mathrm{LOD}$ & 1.45 & 0.25 & 0.11 & 0.11 & 0.05 \\
\hline
\end{tabular}

$T P C$ total phenolic compounds, $H M F$ hydroxymethylfurfural, $L O D 0.012 \mathrm{mg} / \mathrm{L}$ (furfural), $1.120 \mathrm{mg} / \mathrm{L}$ (levulinic acid), $0.970 \mathrm{mg} / \mathrm{L}$ (HMF), $0.009 \mathrm{mg} / \mathrm{L}$ (TPC), $0.003 \mathrm{mg} / \mathrm{L}$ (monosugars and cellobiose)

in Tables 4 and 5. The content of cellulose, hemicellulose and lignin were determined in raw material and in solid-state residues after alkaline pre-treatment with MEA and in solid-state residues after enzymatic hydrolysis (Table 4).

According to the data presented in Table 4, it can be concluded that prior to pre-treatment steps, the composition of solid-state residues changes significantly during alkaline and enzymatic hydrolysis. Even though lignins are extremely resistant to chemical and enzymatic degradation (Alvira et al. 2010; Brodeur et al. 2011; Kumar et al. 2015a; Bali et al. 2015; Abudi et al. 2016), a significant removal of this constituent has been determined during MEA-pre-treatment. In further steps, i.e., during enzymatic hydrolysis, the lignin removal was lower than the limit of detection. In general, lignin removal occurred higher for cereal type of biomass than for grass and wood. Recent progress in lignin removal during pre-treatment is widely discussed in the literature (Kumar et al. 2015b; Kumar and Sharma 2017). According to Michalska and Ledakowicz (2013), the application of sodium hydroxide during pre-treatment leads to almost complete lignin removal. In addition, biological methods are successfully applied to remove lignin during pre-treatment steps (Schilling et al. 2009). Hemicellulose removal was also observed during pre-treatment. At both MEA-pretreatment stage, and enzymatic hydrolysis stage, in case of this polymer, a comparable removal was observed for all used biomasses. Similar effects are reported in the literature for alkaline pre-treatment of Miscanthus sinensis (Haque et al. 2013), 
or diversified biomass types (Yu et al. 2016). However, most of the constituent was hydrolyzed during enzymatic hydrolysis. When cellulose, an unbranched linear polymer is concerned, no significant change in its content was observed during MEA-pretreatment. However, after enzymatic hydrolysis of the separated solid-state residue after MEA-pretreatment, $99.5 \%$ of initial cellulose was hydrolyzed in wood type biomass, i.e., in beech samples. The hydrolysis rate of cellulose in cereal and grass remains at similar level, of $91.2 \%$ for triticale and $91.8 \%$ for meadow grass. The ethanol extractives represent a minor fraction of lignocellulosic materials. Their presence was only identified and determined in raw biomass. This is due to their chemical structure, as this group contains soluble substances, i.e. terpenoids and steroids, fats and waxes, phenolic constituents, and inorganic components (Taherzadeh and Karimi 2007) that were removed in the initial stage of each biomass processing.

In conclusion, the presented data seem to confirm that the MEA-pre-treatment step is well optimized as it allows removing high amount of lignin and its derivatives. Moreover, the enzymatic cocktail composition seems to be composed adequately to the biomass of diversified origin, as it is able to convert most of cellulose present in analysed biomass into less complex structures, i.e., monosugars.

The obtained results regarding solid-state residue streams need to be compared with the results obtained for liquid streams. According to the data presented in Table 5, it can be concluded that the changes in composition of liquid streams, i.e. alkaline and enzymatic hydrolysates correspond with the changes observed in raw material and solid-state residues after pre-treatment steps.

The loss of lignin amount during MEA-pre-treatment is strongly correlated with the high concentration of TPC, HMF, furfural and levulinic acid in the alkaline hydrolysate. In addition, the highest amount of mentioned substances was found in alkaline hydrolysate of triticale (remarkable higher than concentrations of these compounds for other examined types of biomasses). Lignin and hemicellulose removal during the first step was the highest in case of this type of biomass. Similar results were obtained in literature with respect to ionic liquid pre-treatment (Hernández et al. 2013) and Eichhornia crassipes pre-treatment (Xie et al. 2011). Saccharification occurring in the MEA-pretreatment step is poor, as the determined reducing sugar and cellobiose concentration were low in comparison with the ones measured in enzymatic hydrolysates. Obtained results conduct that the approach for stream separation is reasonable, as the alkaline hydrolysates contain high concentrations of byproducts that may be used prior to bio refining and the enzymatic hydrolysate contains mainly reducing sugar components, which can be directly introduced as feed in the dark fermentation broths or for other biofuel generation processes. This approach is justified as in the context of the separation of components, fermentation inhibitors have not been identified in the enzymatic hydrolysate stream or their concentration is below the detection limit (Table 5).

\section{Analysis of the structure of lignocellulosic biomass at different pre-treatment steps}

Analysis of the results regarding biomass composition at different stages of pre-treatment revealed that differences in the solubility of lignin from diversified origin in MEA-solution have a strong influence on the solid-state residue content. According to the literature, another parameter for the lignin removal and efficient saccharification is also the proportion between the constituents, i.e. lignin, hemicellulose and cellulose in the raw material, or in presented case in the solidstate residue after MEA-pre-treatment. The changes in the structure were observed using SEM and EDX measurements. In Fig. 1, SEM images of investigated lignocellulosic materials at further steps of pre-treatment are presented.

Analysis of changes occurring during pre-treatment steps based on SEM images reveals that during consecutive steps numerous cracks occur in the structure of biomass. Differences between SEM pictures taken for raw materials (see Fig. 1a, d, g) structures and for MEA-pre-treated solid-state residue (see Fig. 1b, e, h) result from the delignification occurring in this stage. The migration and reorganization of the biomass structure is the main reason for occurring changes. Triticale and meadow grass surfaces, for which lignin is peripherally located (Kucharska et al. 2018), is more scarified, than beech surface. Differences between SEM pictures taken for MEA-pre-treated solid-state residues (see Fig. 1b, e, h) and solid residues after enzymatic hydrolysis (see Fig. 1c, f, i) structures result from the saccharification occurring in this stage. An observation regarding the total biomass amount recovery presented in Table 3 . Corresponded with the material distribution visualized on presented pictures. The size and the scarification of the materials surface confirm deep changes that have occurred in the structure.

The results concerning EDX measurements for selected elemental composition (Table 6) confirm that processes occurring during the delignification and saccharification cause only proportional changes in the elemental composition of the biomass.

\section{Changes in the Fourier transform infrared (FTIR) spectra}

FTIR spectroscopy of raw biomass and solid-state residues after pre-treatment processes may deliver information 

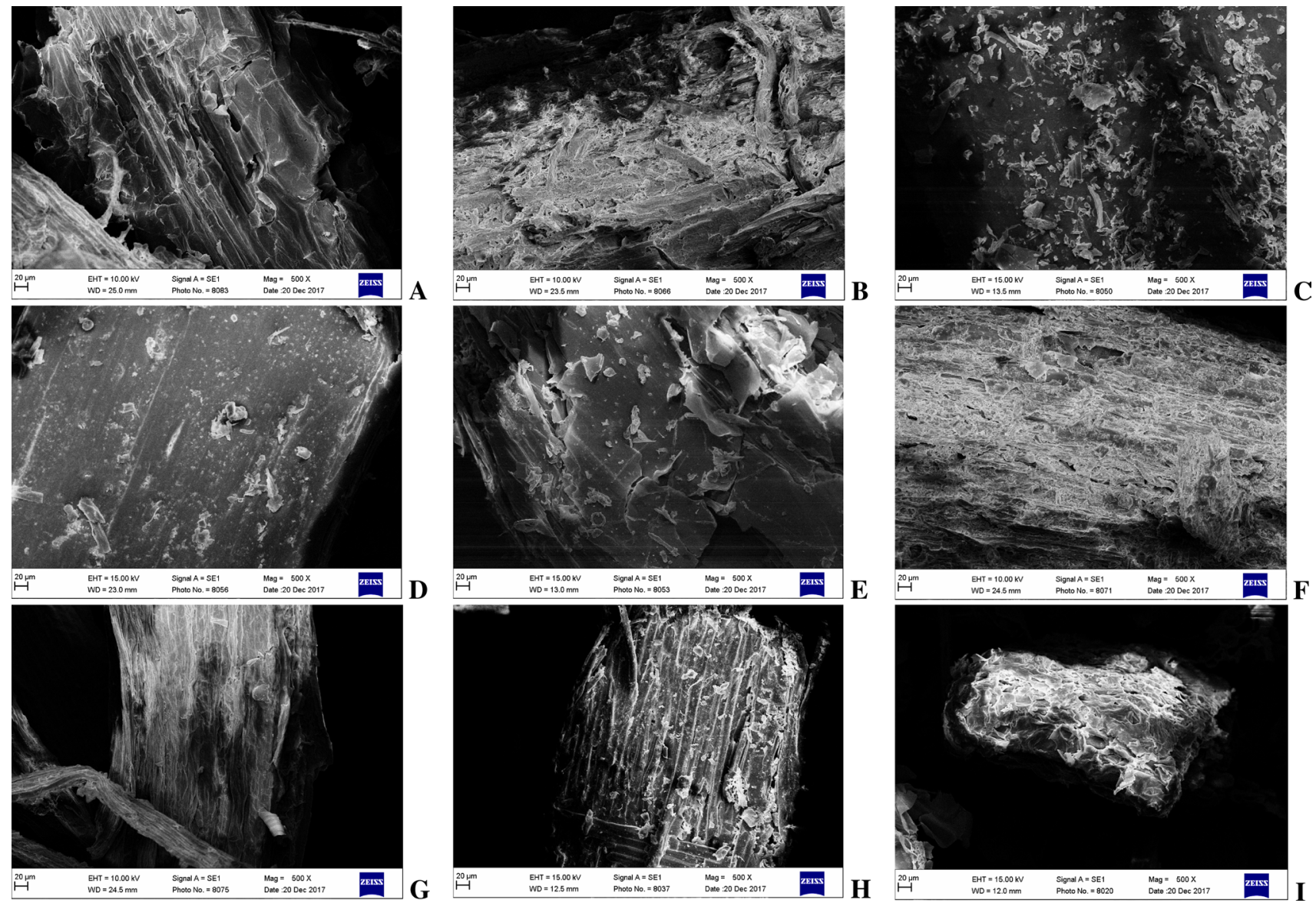

Fig. 1 SEM images of investigated lignocellulosic materials: a raw TP, b MEA-pre-treated TP, $\mathbf{c}$ residue after TP enzymatic hydrolysis, $\mathbf{d}$ raw MG, e MEA-pre-treated MG, $\mathbf{f}$ residue after MG enzymatic hydrolysis, $\mathbf{g}$ raw B, $\mathbf{h}$ MEA-pre-treated B, $\mathbf{i}$ residue after B enzymatic hydrolysis

Table 6 Results of EDX measurements for selected elemental composition of raw material and solid-state residue after enzymatic hydrolysis

\begin{tabular}{|c|c|c|c|c|c|c|c|c|c|c|c|c|}
\hline \multirow[t]{3}{*}{ Element } & \multicolumn{4}{|c|}{ Triticale } & \multicolumn{4}{|c|}{ Meadow grass } & \multicolumn{4}{|l|}{ Beech } \\
\hline & \multicolumn{2}{|l|}{ Raw } & \multicolumn{2}{|c|}{$\begin{array}{l}\text { Enzymatic } \\
\text { pre-treated }\end{array}$} & \multicolumn{2}{|l|}{ Raw } & \multicolumn{2}{|c|}{$\begin{array}{l}\text { Enzymatic } \\
\text { pre-treated }\end{array}$} & \multicolumn{2}{|l|}{ Raw } & \multicolumn{2}{|c|}{$\begin{array}{l}\text { Enzymatic } \\
\text { pre-treated }\end{array}$} \\
\hline & wt. \% & SD & wt. \% & SD & wt. \% & SD & wt. $\%$ & SD & wt. $\%$ & SD & wt. $\%$ & SD \\
\hline $\mathrm{C}$ & 45.66 & 5.35 & 48.42 & 5.65 & 47.55 & 5.70 & 42.24 & 5.16 & 53.01 & 6.02 & 52.67 & 5.98 \\
\hline $\mathrm{O}$ & 49.49 & 5.84 & 47.98 & 5.76 & 44.25 & 5.46 & 48.69 & 5.87 & 46.03 & 5.46 & 46.51 & 5.55 \\
\hline $\mathrm{Si}$ & 3.01 & 0.15 & 0.86 & 0.06 & 2.08 & 0.11 & 4.38 & 0.21 & 0.06 & 0.03 & - & - \\
\hline $\mathrm{K}$ & 0.79 & 0.05 & 1.17 & 0.06 & 2.88 & 0.11 & 2.17 & 0.09 & 0.21 & 0.03 & 0.15 & 0.03 \\
\hline $\mathrm{Ca}$ & 0.28 & 0.03 & 0.86 & 0.05 & 1.02 & 0.05 & 1.32 & 0.07 & 0.13 & 0.03 & 0.29 & 0.04 \\
\hline $\mathrm{Mg}$ & 0.19 & 0.03 & 0.11 & 0.03 & 0.17 & 0.03 & 0.18 & 0.04 & 0.11 & 0.03 & 0.06 & 0.03 \\
\hline
\end{tabular}

regarding the changes in the biomass structure during the consecutive steps of pre-treatment. There are some specific wavelengths which are expected to occur in the spectrum of biomass sample. The FTIR spectrum for raw biomasses and solid-state residues after alkaline and enzymatic hydrolysis are presented in Fig. 2. The typical occurring bands regarding the spectra are discusses further.
For each registered spectra, a strong broad band at $3433 \mathrm{~cm}^{-1}$ can be observed. Its presence is related both to the presence of aromatic and aliphatic hydroxyl groups. At the progress of pre-treatment, the band tends to lower its amplitude, as the concentration of components decreases. One needs, however, to remember, that the analysis is carried for solid-state residues, therefore, there is no straight correlation between the absorbance intensity and the concentration. 

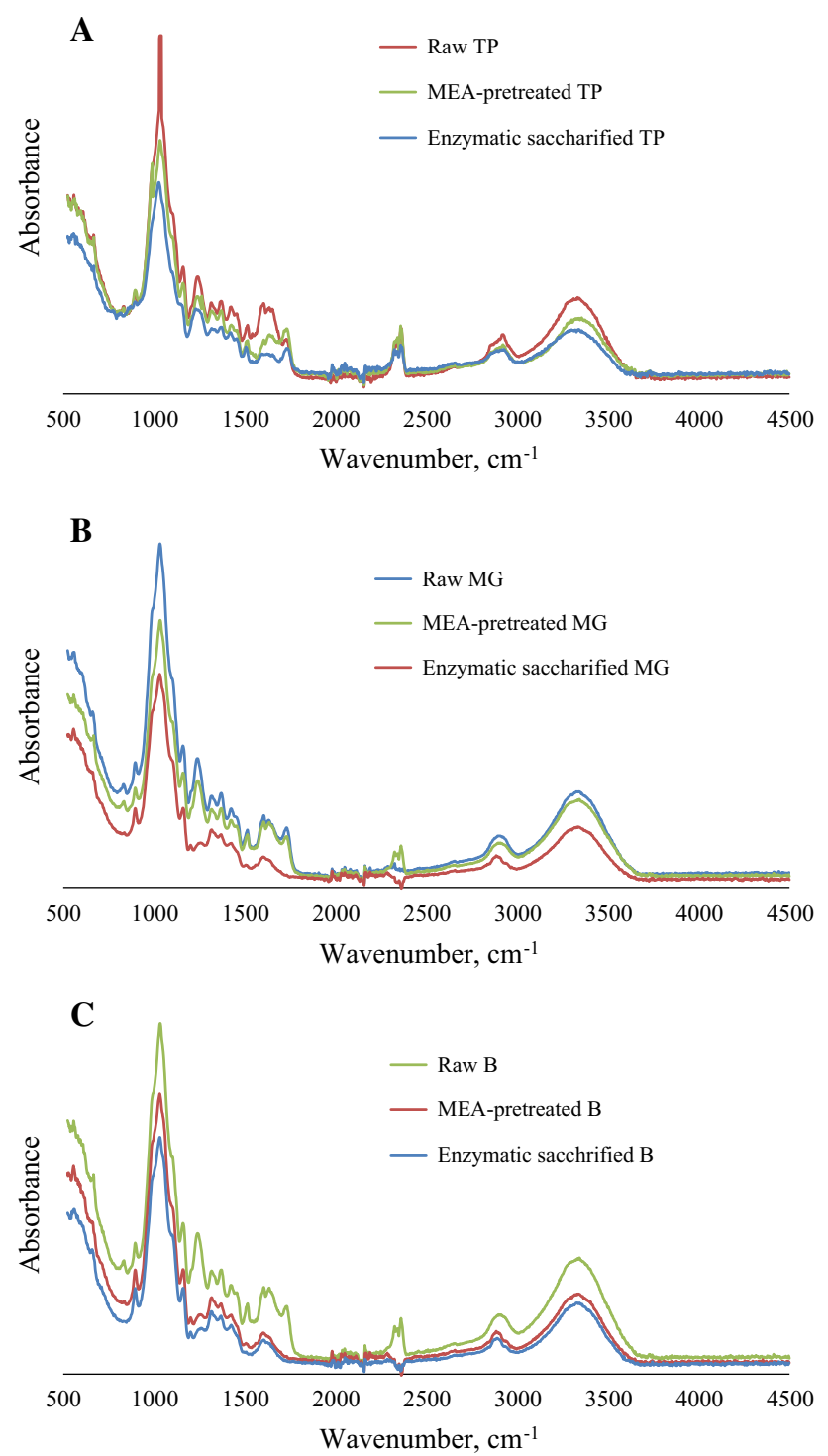

Fig. 2 FTIR spectra for raw biomasses and solid-state residues after MEA-pretreatment and enzymatic hydrolysis for a triticale, b meadow grass, and $\mathbf{c}$ beech

The band occurring at $2955 \mathrm{~cm}^{-1}$ may be caused by $\mathrm{C}-\mathrm{H}$ stretch vibrations in the methoxyl, methyl and methylene groups present in the aromatic and saccharidic structures of the hydrolyzed products. The presence of this band was expected, as for all parts of lignocellulosic constituents, bands related to monosaccharide presence occur. The intensity of absorbance at $2955 \mathrm{~cm}^{-1}$ decreases with the progress of saccharification, which can also be observed on presented spectra (Fig. 2). The effect is more visible for beech (see Fig. 2c), which corresponds well with the cellulose removal presented in Table 1. The narrow bands at $1639 \mathrm{~cm}^{-1}$ and $1567 \mathrm{~cm}^{-1}$ may be assigned to the presence of ketones, carbonyls and ester groups in the biomass lignin and hemicelluloses. This kind of bands decreases mainly during delignification via MEA-pretreatment. The presence of lignin structures in the biomass is also determined by the absorbance at $1414 \mathrm{~cm}^{-1}$, assigned to skeletal vibrations and carbonyl group stretching vibrations in the syringyl and guaiacyl aromatic rings, parts of the lignin structures. The $\mathrm{CH}_{2}$ deformation vibrations appearing at $1351 \mathrm{~cm}^{-1}$ and may be caused by both lignin and hemicelluloses structures. The bands in the wavelengths of $1110-800 \mathrm{~cm}^{-1}$ are typical for hemicelluloses $(\mathrm{C}-\mathrm{C}$ ring vibrations, stretching vibrations of $\mathrm{C}-\mathrm{OH}$ side groups, $\mathrm{C}-\mathrm{O}-\mathrm{C}$ glucosidic band vibrations). The band at $1047 \mathrm{~cm}^{-1}$ is typical for xylan C-O-C stretching of glucosidic linkages. In conclusion, FTIR spectra may deliver information regarding the changes in the structure of biomass during pre-treatment.

\section{Conclusions}

Optimization of saccharification conditions of lignocellulosic biomass for biofuels generation via fermentation processes is crucial as the process efficiency is concerned. The optimization employing Box-Behnken design may be a good approach as it revealed, that even though using diversified lignocellulosic biomass residues in different conditions, when different values of monosugars efficiency has been reached, the optimal operating conditions and the composition of saccharification enzymatic cocktail seems to be universal, and the optimal values regarding the model can be applied to various biomass materials. The application of several techniques to analyze the obtained solid and liquid streams produced during the pre-treatment procedure revealed several structural and composition changes in the biomass. Therefore, FTIR spectra, SEM pictures and HPLC analysis can be successfully applied to measure the development of the process.

Acknowledgements This work was carried out within the framework of the project "Studies of alkaline hydrolysis of lignocellulosic biomass and conversion conditions of hydrolyzed products to biogases", supported financially by the National Science Center through the Grant UMO-2014/13/B/ST8/04,258.

Author contributions Karolina Kucharska and Hubert Cieśliński conceived and designed the experiments. Karolina Kucharska and Edyta Słupek carried the experiments. Karolina Kucharska wrote the paper. Marian Kamiński provided materials/reagents/apparatus.

\section{Compliance with ethical standards}

Conflict of interest The authors declare no conflict of interest. The founding sponsors had no role in the design of the study; in the collection, analyses, or interpretation of data; in the writing of the manuscript, and in the decision to publish the results. 
Open Access This article is distributed under the terms of the Creative Commons Attribution 4.0 International License (http://creativeco mmons.org/licenses/by/4.0/), which permits unrestricted use, distribution, and reproduction in any medium, provided you give appropriate credit to the original author(s) and the source, provide a link to the Creative Commons license, and indicate if changes were made.

\section{References}

Abudi ZN, Hu Z, Xiao B, Abood AR, Rajaa N, Laghari M (2016) Effects of pretreatments on thickened waste activated sludge and rice straw co-digestion: experimental and modeling study. J Environ Manag 177:213-222

Agbor VB, Cicek N, Sparling R, Berlin A, Levin DB (2011) Biomass pretreatment: fundamentals toward application. Biotechnol Adv 29:675-685

Alvira P, Tomas-Pejo E, Ballesteros M, Negro MJ (2010) Pretreatment technologies for an efficient bioethanol production process based on enzymatic hydrolysis: a review. Bioresour Technol 101:4851-4861

Anwar Z, Gulfraz M, Irshad M (2014) Agro-industrial lignocellulosic biomass a key to unlock the future bio-energy: a brief review. J Radiat Res Appl Sci 7(2):163-173

Balat M (2011) Production of bioethanol from lignocellulosic materials via the biochemical pathway: a review. Energy Convers Manag 52:858-875. https://doi.org/10.1016/j.enconman.2010.08.013

Bali G, Meng X, Deneff JI, Sun Q, Ragauskas AJ (2015) The Effect of alkaline pretreatment methods on cellulose structure and accessibility. Chem Sus Chem 8:275-279

Brodeur G, Yau E, Badal K, Collier J, Ramachandran KB, Ramakrishnan S (2011) Chemical and physicochemical pretreatment of lignocellulosic biomass: a review. Enzyme Res 2011:e787532

Dahunsi OS, Oranusi S, Efeovbokhan EV (2017) Anaerobic monodigestion of Tithonia diversifolia (Wild Mexican sunflower). Energy Convers Manag 148:128-145. https://doi.org/10.1016/j. enconman.2017.05.056

Haque MA, Barman DN, Kang TH, Kim MK, Kim J, Kim H, Yun HD (2013) Effect of dilute alkali pretreatment on structural features and enhanced enzymatic hydrolysis of Miscanthus sinensis at boiling temperature with low residence time. Biosyst Eng 114:294305. https://doi.org/10.1016/j.biosystemseng.2013.01.006

Hasegawa I, Khoo TH, Mae K (2013) Direct saccharification of lignocellulosic biomass by hydrolysis with formic acid solution. Green Process Synth 2:143-149

Hernández JJ, Ballesteros R, Aranda G (2013) Characterisation of tars from biomass gasification: Effect of the operating conditions. Energy 50:333-342. https://doi.org/10.1016/j.energy.2012.12.005

Ko JK, Bak JS, Jung MW, Lee HJ, Choi I-G, Kim TH, Kim KH (2009) Ethanol production from rice straw using optimized aqueousammonia soaking pretreatment and simultaneous saccharification and fermentation processes. Bioresour Technol 100:4374-4380. https://doi.org/10.1016/J.BIORTECH.2009.04.026

Kucharska K, Łukajtis R, Słupek E, Cieśliński H, Rybarczyk P, Kamiński M (2018) Hydrogen production from energy poplar preceded by MEA pre-treatment and enzymatic hydrolysis. Molecules 23:1-21. https://doi.org/10.3390/molecules23113029

Kumar AK, Sharma S (2017) Recent updates on different methods of pretreatment of lignocellulosic feedstocks: a review. Bioresour Bioprocess 4:7-14

Kumar G, Bakonyi P, Periyasamy S, Kim SH, Nemestóthy N, BélafiBakó K (2015a) Lignocellulose biohydrogen: practical challenges and recent progress. Renew Sustain Energy Rev 44:728-737
Kumar G, Bakonyi P, Periyasamy S, Kim SH, Nemestóthy N, BélafiBakó K (2015b) Lignocellulose biohydrogen: practical challenges and recent progress. Renew Sustain Energy Rev 44:728-737

Lalak J, Kasprzycka A, Murat A, Paprota EM, Tys J (2014) Pretreatment methods of lignocelulosic biomass to improve methane fermentation process (a review). Acta Agrophysica 21(1):51-62

Lay JJ (2001) Biohydrogen generation by mesophilic anaerobic fermentation of microcrystalline cellulose. Biotechnol Bioeng 74:280 287. https://doi.org/10.1002/bit.1118

Lay JJ, Tsai CJ, Huang CC, Chang JJ, Chou CH, Fan KS, Chang JI, Hsu PC (2005) Influences of $\mathrm{pH}$ and hydraulic retention time on anaerobes converting beer processing wastes into hydrogen. Water Sci Technol 52:123-129

Łukajtis R, Rybarczyk P, Kucharska K, Konopacka-Łyskawa D, Słupek E, Wychodnik K, Kamiński M (2018) Optimization of saccharification conditions of lignocellulosic biomass under alkaline pretreatment and enzymatic hydrolysis. Energies 11(4):886. https:// doi.org/10.3390/en11040886

Michalska K, Ledakowicz S (2013) Alkali pretreatment of Sorghum Moench for biogas production. Chem Pap 67(9):1130-1137

Narra M, James JP, Balasubramanian V (2015) Simultaneous saccharification and fermentation of delignified lignocellulosic biomass at high solid loadings by a newly isolated thermotolerant Kluyveromyces sp. for ethanol production. Bioresour Technol 179:331-338

Nowak P, Łukajtis R, Kamiński M (2017) Zastosowanie wysokosprawnej kolumnowej chromatografii cieczowej w odwróconych układach faz (RP-HPLC) do rozdzielania i wstępnej identyfikacji składników hydrofilowych mieszanin po hydrolizie zasadowej biomasy ligno-celulozowej (BMLC). Camera Sep 9(2):131-154

Sangyoka S, Reungsang A, Lin C-Y (2016) Optimization of biohydrogen production from sugarcane bagasse by mixed cultures using a statistical method. Sustain Environ Res 26:235-242. https://doi. org/10.1016/j.serj.2016.05.001

Schilling JS, Tewalt JP, Duncan SM (2009) Synergy between pretreatment lignocellulose modifications and saccharification efficiency in two brown rot fungal systems. Appl Microbiol Biotechnol 84:465-475. https://doi.org/10.1007/s00253-009-1979-7

Sekoai P (2016) Modelling and optimization of operational setpoint parameters for maximum fermentative biohydrogen production using Box-Behnken design. Fermentation 2:15-22. https://doi. org/10.3390/fermentation2030015

Sluiter A, Hames B, Hyman D, Payne C, Ruiz R, Scarlata C, Sluiter J, Templeton D (2008c) Determination of total solids in biomass and total dissolved solids in liquid process samples; Technical Report NREL/TP-510-42621; NREL: Golden, CO, USA, p. 9

Sluiter A, Hames B, Ruiz R, Scarlata C, Sluiter J, Templeton D (2008a) Determination of ash in biomass: laboratory analytical procedure (LAP); Technical Report NREL/TP-510-42622; NREL: Golden, CO, USA

Sluiter A, Hames B, Ruiz R, Scarlata C, Sluiter J, Templeton D (2008b) Determination of sugars, byproducts, and degradation products in liquid fraction process samples; Technical Report NREL/TP-51042623; NREL: Golden, CO, USA, pp 1-14

Słupek E, Makoś P, Kamiński M (2018) Metodyka oznaczania sumarycznej zawartości inhibitorów fermentacji ciemnej oraz monocukrów w brzeczkach fermentacyjnych techniką HPLCRID-UV-VIS/DAD. Camera Sep 10(2):52-63

Sun Y, Cheng J (2002) Hydrolysis of lignocellulosic materials for ethanol production: a review. Bioresour Technol 83:1-11

Taherzadeh MJ, Karimi K (2007) Enzyme-based hydrolysis processes for ethanol from lignocellulosic materials: a review. Bio Resour 2(4):707-738

Trzcinski AP, Stuckey DC (2015) Contribution of acetic acid to the hydrolysis of lignocellulosic biomass under abiotic conditions. Bioresour Technol 185:441-444 
Wikandari R, Millati R, Taherzadeh MJ (2016) Pretreatment of lignocelluloses with solvent $N$-methylmorpholine $N$-oxide. In: Mussatto SI (ed) Biomass Fractionation Technologies for a Lignocellulosic Feedstock Based Biorefinery. Elsevier Inc., São Paulo, Brazil, pp 255-280. https://doi.org/10.1016/B978-0-12-80232 3-5.00012-8

Xie XF, Wang M, Zhang RG, Li J, Qing-Yuan Y (2011) The role of emotions in risk communication. Risk Anal 31(3):450-465. https ://doi.org/10.1111/j.1539-6924.2010.01530.x

Yu Q, Zhuang X, Wang W, Qi W, Wang Q, Tan X, Kong X, Yuan $Z$ (2016) Hemicellulose and lignin removal to improve the enzymatic digestibility and ethanol production. Biomass Bioenerg 94:105-109. https://doi.org/10.1016/j.biombioe.2016.08.005

Publisher's Note Springer Nature remains neutral with regard to jurisdictional claims in published maps and institutional affiliations. 